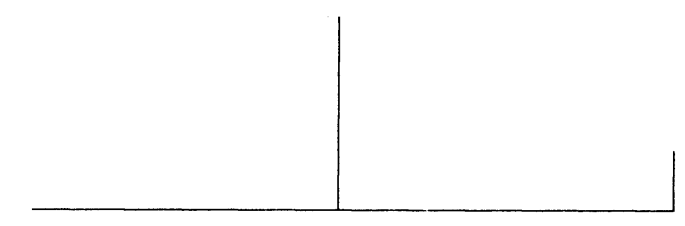

Rev. Latinoam. Psicopat. Fund., VII, 2, 97-109

\title{
Notas sobre o ambiente que cerca a prática da medicina nos Estados Unidos
}

Mônica Teixeira

A seção "Observando a Medicina" apareceu em março de 2001, fruto da estupefação de seus editores. Espantava-os então, e continua a espantá-los hoje, a complexidade da estrutura nascida do procedimento de legitimação que autoriza um laboratório farmacêutico a produzir e vender medicamentos. Foi a pergunta a respeito da qualidade dos efeitos dessa estrutura sobre a delicada relação do clínico com aquele que o procura em busca de alívio para seu sofrimento, que fez o olhar da seção pousar sobre outros aspectos do entorno da prática da medicina na vida contemporânea. Seguidas vezes, o olhar dos observadores se viu capturado pela surpresa ante a imbricação complexa entre o negócio da medicina e a prática médica, em especial no maior país do mundo, os Estados Unidos da América. Nesta edição, aconteceu de novo: é a economia da medicina que domina a paisagem, vista através da leitura do mais influente jornal do mundo - o New York Times -, e das notícias reveladas por certas revistas científicas.

Penso que as palavras da mídia são apropriadas pelo humano e afetam a constituição de seu ambiente psíquico. Se é assim, o ambiente no qual os médicos se entregam à prática clínica é afetado pelas injunções apresentadas ao público como as determinantes para a medicina de hoje. À mídia, interessa o financiamento, o preço, o custo, o gasto. Sobre o encontro médico-paciente, poucas palavras são pronunciadas. 


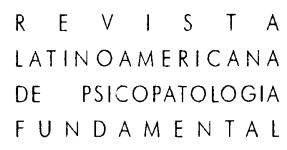

É o espanto diante de tamanho silêncio que sustenta as notícias reunidas nesta edição.

Os grandes números do consumo de medicamentos nos EUA, e fora dos EUA

As drogas que diminuem o nível de colesterol LDL, chamadas estatinas, venderam US\$14 bilhões em 2003. As destinadas a evitar azia, gastrite, úlceras, US\$ 13 bilhões. Os antidepressivos, US\$ 11 bilhões. A quarta classe de medicamentos mais consumidos no país são os antipsicóticos, que venderam US $\$ 6,4$ bilhões em 2002. Em 2003, o uso de drogas que afetam o sistema nervoso central cresceu $17 \%$. No mundo, também em 2003, as vendas de remédios no varejo alcançaram US $\$ 317$ bilhões. Os norte-americanos dos Estados Unidos, sozinhos, compraram US $\$ 163$ bilhões em drogas $-57 \%$ do consumo da humanidade.

\section{Os valores envolvidos no mercado de drogas, ontem e hoje}

Há 50 anos, as drogas mais vendidas nos Estados Unidos, segundo a IMS Health - empresa especializada na análise do mercado farmacêutico, eram Bufferin (ácido acetilsalicílico) e Geritol, complexo vitamínico. A receita da Johnson \&Johnson era de US $\$ 204$ milhões, contra US\$ 36 bilhões em 2004. Em 1954, a Merck vendia US $\$ 1,5$ milhões; em 2002, vendeu US $\$ 52$ bilhões.

\section{Os gastos com drogas na Grã Bretanha}

Em três anos, os gastos com medicamentos do National Health Service, o sistema público de saúde britânico, subiu quase 50\% - de 2,3 bilhões de libras para 7,2 bilhões.

\section{O consumo de antidepressivos entre as crianças}

Segundo estudo do Centro de Controle e Prevenção de Doenças, órgão do governo norte-americano, é entre as crianças em idade pré-escolar que mais cresce agora a prescrição de antidepressivos. Outro estudo do CDC descobriu 


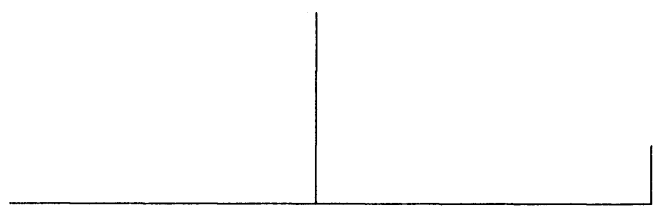

que, em 2002, os médicos (não necessariamente psiquiatras) ministraram antidepressivos, por três meses ou mais, a 10 milhões de crianças no país. Dados assim levaram o Conselho de Bioética da Casa Branca a manifestar, em relatório, sua preocupação com o fato de que "tudo na vida se tornou um problema médico". O texto apresenta uma lista de fatos da vida que foram medicalizados: nascimento, infertilidade, práticas e costumes sexuais, aspectos do comportamento criminoso, ansiedade, nervosismo, velhice, morte, tristeza e luto. "A busca da felicidade e da autoperfeição tornou-se assunto dos médicos", escreveram os conselheiros.

\section{O mercado da "disfunção erétil”"}

O Viagra (sildenafil) tornou a Pfizer a maior companhia farmacêutica do mundo. Hoje, o medicamento lançado em 1998 tem dois competidores: Levitra (GlaxoSmithKline) e Cialis (Lilly Icos). A indústria farmacêutica estima em 30 milhões o número de norte americanos que enfrentam problemas em ter ou manter ereções. Também estima que apenas $13 \%$ desses homens estão sendo tratados - para a indústria, do que se trata nessas estimativas é o espaço para expandir a medicalização da impotência e da ejaculação precoce. No caso da "disfunção erétil", estimular e fomentar a tendência significa - contas da Lehman Brothers, empresa de análise de investimentos - mais que triplicar as vendas de medicamentos da classe até 2010. Em 2004, as três fabricantes planejam gastar US\$ 300 milhões em publicidade. Só na transmissão do campeonato esportivo Super Bowl, as fabricantes de Cialis e Levitra compraram espaço publicitário a US\$ 4 milhões o anúncio de um minuto. As agências donas das contas exultam, mas há dificuldades na propaganda dos produtos. É medicamento que só se compra com receita (como é usual nos EUA). Por isso, há regulação federal a respeito do que um anúncio pode ou não dizer. Exemplo: se o comercial explicitar o nome do medicamento e para que ele serve, então é obrigatório mencionar efeitos colaterais. No caso de uma dessas marcas, o anúncio deveria informar que ereção provocada pela ingestão do medicamento pode durar quatro horas.

Diferença entre os sexos atrapalha os negócios da Pfizer

As mulheres decepcionaram os pesquisadores da Pfizer, observou Gardiner Harris, escrevendo para o New York Times, dia 28 de fevereiro. Durante oito anos; esses pesquisadores encetaram ensaios clínicos em busca de evidências 


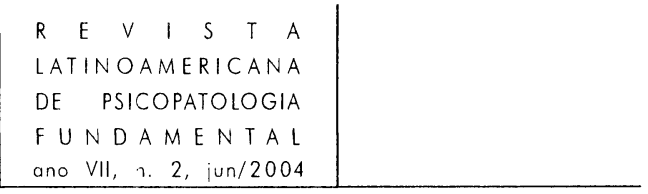

do efeito do sildenafil sobre a "função sexual" de três mil mulheres. Se as tivessem encontrado, a Pfizer poderia incorporar o sexo feminino ao mercado do blockbuster Viagra. O jornal registrou a "consternação" do fabricante ao desistir da empreitada. "O problema", explicaram os pesquisadores ao jornal, "é que homens e mulheres têm uma relação fundamentalmente diferente entre estimulação sexual e desejo". A impossibilidade de transformar a excitação das mulheres em algo mensurável como a ereção dos homens consternou os pesquisadores: “... apesar de o medicamento ter produzido sinais externos de estimulação nas mulheres, isto parece afetar pouco seu desejo", relata a reportagem. Todas essas afirmações advieram dos resultados de vários ensaios clínicos, e levaram o chefe da pesquisa, Mitra Boolel, a concluir: "O cérebro é o órgão sexual crucial da mulher".

\section{Desenho do primeiro ensaio clínico, sildenafil versus placebo, para mulheres}

Os pesquisadores (e pesquisadoras) contaram ao jornal o que inventaram: a seis mulheres, ministraram Viagra; a seis outras, placebo. Exibiram então vídeos eróticos a todas elas; sentadas, usavam sondas pélvicas para medir alterações no fluxo sanguíneo genital.

\section{Curta, sobre medicalização}

Mas sildenafil pode ser efetivo para algumas mulheres, informa um psiquiatra norte americano. Mulheres que perderam o desejo sexual por tomarem antidepressivos podem recuperá-lo usando o medicamento.

\section{Um rato é um homem?}

Ratos de laboratório jogados numa piscina de água são monitorados para medir o tempo que nadam antes de desistir. Os ratos a quem os pesquisadores ministram antidepressivos nadam mais tempo. Os pesquisadores também penduram os ratos pelo rabo; aqueles sob antidepressivos lutam mais tempo antes de desistir. É esse o recurso usado pela indústria farmacêutica para selecionar drogas contra a depressão em testes pré-clínicos. São modelos, justificam os farmacologistas - dos quais não se deriva que ratos sofrem de depressão. Mas 


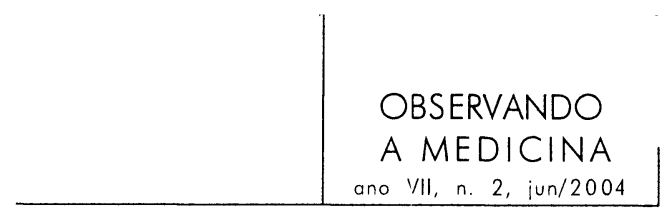

esse detalhe é sofisticado demais para os jornalistas escrevendo sobre "depressão" nos periódicos de massa.

\section{O poder da propaganda, história de uma médica contada sobre um seu colega}

A médica chama-se Abigail Zuger, e escreveu ensaio publicado no dia 24 de fevereiro no New York Times:

Há certo tempo, uma nova droga contra a aids foi introduzida no mercado, com algumas características que a diferenciavam de drogas mais antigas. Por um lado, a potência da nova classe de drogas não estava completamente estabelecida; por outro, era uma droga de ação prolongada que poderia ser ingerida apenas uma vez ao dia - detalhe libertador e maravilhoso para pacientes submetidos a esquemas de medicamentos a serem ministrados duas ou três vezes ao dia. A droga foi lançada com o mínimo de informação publicada sobre seu sucesso com pacientes - uma ocorrência não rara nestes dias de rápida aprovação de drogas. Os representantes da companhia farmacêutica superaramse a si mesmos, introduzindo o novo produto com almoços, jantares e grupos de discussão em lugares longínquos.

Um amigo, um tanto cético a respeito da droga, usou todas essas oportunidades para aprender sobre ela. Depois de muitas conversas com os representantes, meia dúzia de ótimas refeições e algumas viagens para praias com clima quente, ele estava cheio de informação.

O tempo passou. Mais estudos foram feitos. A nova droga pareceu ser menos efetiva do que se esperava. Conselhos consultivos começaram a avisar que, em certas situações, a nova droga não deveria em absoluto ser usada: era tão ineficaz que poderia colocar os pacientes em risco.

Meu amigo, consciencioso, verificou sua lista de pacientes para identificar aqueles portadores de HIV a quem prescrevera a droga, para contatálos e mudar a medicação. Na próxima vez em que estivemos juntos, encontrei-o com uma nova consciência do poder da propaganda subliminar. "Eu receitei aquela droga para muita gente", ele me disse. "Sinceramente, não imagino como isso pôde acontecer".

\section{Fato raramente visto no mundo da Medicina Baseada em Evidências}

A Bristol-Myers Squib fabrica a estatina Pravachol (pravastatin), para reduzir níveis de colesterol LDL. Mercado em 2003: US\$2,8 bilhões, ainda o campeão 


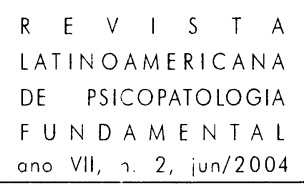

de vendas da empresa, mas com participação minguante de $9 \%$ do mercado mundial de estatinas. A Pfizer fabrica Lipitor (atorvastin), outra estatina, feita também para reduzir níveis de colesterol LDL. Em 2000, a Bristol encomendou a pesquisadores da Escola de Medicina de Harvard um estudo para comparar o efeito de sua estatina, contra o efeito da estatina da Pfizer. Para a Bristol, Pravachol e Lipitor se equivaliam na prevenção do ataque cardíaco.

Os pesquisadores de Harvard aceitaram realizar os ensaios clínicos sob a exigência de os resultados serem publicados imediatamente após a conclusão do estudo, quaisquer que fossem eles. Deu no New England Journal of Medicine, 8 de abril: em 4.162 pessoas que tiveram ataque cardíaco, acompanhadas durante dois anos, a estatina da Pfizer, Lipitor, reduziu mais fortemente os níveis de colesterol do que a estatina da Bristol. O estudo provou mais, segundo a interpretação dos cardiologistas: quanto mais baixo o nível de colesterol LDL em quem sofre do coração (e há tantos!), tanto menor é a chance de ataque cardíaco.

A patrocinadora Bristol chamou o estudo de Prove It (Pravastatin or Atorvastatin Evaluation and Infection Therapy). "De fato, eles provaram", deliciou-se um professor do Baylor College of Medicine. "Mas não acho que tenham provado o que pensavam que provariam. É notável", completou.

Para os fabricantes de estatinas - AstraZeneca, Merck, Schering Plough, Pfizer e mesmo a Bristol -, o resultado do ensaio clínico é notícia ótima: agora, os médicos estarão legitimados a "estatinizar" mais 36 milhões de americanos, por causa da descoberta de que é bom baixar o LDL a níveis menores que os 100 miligramas por decilitro que se recomendava até agora para os cardíacos de alto risco. O mercado alcançado hoje (calculado em $30 \%$ do mercado potencial) é de 11 milhões de pessoas. Mantida essa percentagem de alcance, os novos estatinizados dobram o tamanho do mercado. A Pfizer, por exemplo, terá pressa de alcançá-los: a patente do Lipitor termina em 2010.

Com a divulgação do estudo, as ações da Bristol caíram 33 centavos de dólar, para US\$27,90; e as da Pfizer subiram 34 centavos, para US\$37,51. O resultado, tão fora do usual, de um estudo contrariar o desejo de seu patrocinador, afetou pouco o mercado.

\section{Máquinas de diagnóstico por imagem, uma por consultório}

Além dos gastos com medicamentos, sempre maiores nos Estados Unidos (e em todo o mundo), e com os tratamentos hospitalares, outro item entra na lista dos chamados "custos crescentes" da administração da medicina: as máquinas para diagnóstico por imagens. Nos Estados Unidos, as seguradoras de saúde já 


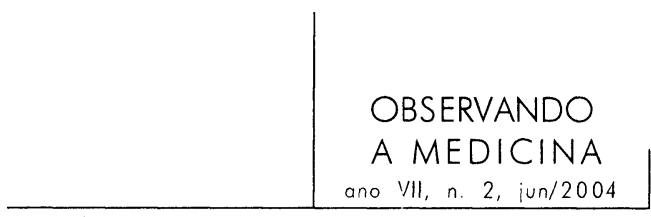

estimam o negócio em quase 100 bilhões de dólares anuais. Com tendência a crescer depressa, como mostra o exemplo de Siracusa, Estado de Nova Iorque. $\mathrm{Na}$ cidade, revela-se uma tendência: médicos, sozinhos ou em grupo, compram máquinas de imagem de grande porte - como tomógrafos, equipamento de ressonância magnética e mesmo os ainda raros tomógrafos de emissão de pósitrons -, instalam-nas em seus consultórios e fornecem eles mesmos o exame que, antes, pediam a seus pacientes para realizar nos hospitais da área. Eles solicitam o exame, que será realizado na máquina que lhes pertence (ou virá a pertencer, quando acabarem de pagá-las). Em 3 anos, desde 2001, cresceu em um terço o número de máquinas de ressonância na área de Siracusa: passou de 20 para 27. De junho de 2002 a junho de 2003, subiu em 23\% o número de exames realizados. A maior companhia seguradora da área (que paga pelos exames) afirma que, em Siracusa, se faz $67 \%$ mais exames de ressonância do que, por exemplo, em Rochester, também no Estado de Nova Iorque.

Uma máquina de ressonância nova custa hoje (preço decrescente, pela escala e pela tecnologia agregada) US $\$ 1,4$ milhões. O preço do exame varia entre US\$ 500 e 700. Nos custos do programa Medicare, do governo federal, que atende os norte-americanos com mais de 65 anos, em cinco anos a despesa com exames de imagem cresceu $50 \%$, contra $30 \%$ nos gastos gerais do programa. $\mathrm{O}$ Estado de Nova Iorque, por decisão do governador George Pataki, estuda reformas no programa Medicaid, co-financiado pelos Estados e pelo governo federal. O grupo de trabalho vai avaliar as consequiências da migração de exames e equipamentos dos hospitais para os consultórios.

\section{Segredo de Polichinelo}

Em dezembro de 2003, Allen Roses, vice-presidente mundial de pesquisa em genética da GlaxoSmithKline, resolveu contar ao jornal The Independent, de Londres, duas ou três coisas conhecidas no setor sobre a efetividade dos produtos que vendem ao público. Segundo ele, mais de $90 \%$ das drogas só funcionam para 30 a $50 \%$ das pessoas que as utilizam. Exemplos dele: as drogas para doença de Alzheimer beneficiam menos de um terço dos pacientes; no geral, as drogas contra o câncer são efetivas em $25 \%$ dos casos. Os medicamentos para osteoporose, artrite, e enxaqueca, funcionam em metade dos pacientes a quem são ministrados.

Essas percentagens se aproximam das alcançadas quando da administração de placebo, o que não foi observado nem pelo jornal nem pelo executivo. Allen Roses resolveu desvelar o segredo de polichinelo porque uma das promessas da 


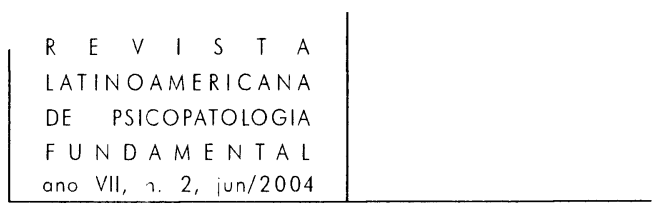

farmacogenômica - sua especialidade - é abrir à indústria a possibilidade de confeccionar medicamentos sob medida para cada paciente, segundo determinações a serem descobertas em genes.

\section{Por exemplo}

Uma em cada dez pessoas (ou menos) com certo tipo de câncer no pulmão que tomam determinado medicamento vêem seus tumores regredir ou desaparecer em meses. Dois grupos de pesquisa pensam ter descoberto a razão pela qual esses $10 \%$ respondem ao medicamento: as células de seus tumores apresentam uma certa mutação genética que as torna vulneráveis à droga. A droga, fabricada pela AstraZeneca, foi aprovada em maio de 2003 para o tratamento do tipo mais comum de câncer no pulmão e recebeu o nome comercial de Iressa (gefitinib). Para a companhia, a notícia é boa e ruim ao mesmo tempo: diminui seu mercado - atualmente 125 mil pacientes com câncer no pulmão usam o medicamento -, porque passará a ser prescrita apenas para aqueles pacientes cujos tumores apresentarem a mutação; ou pode aumentá-lo - se a mesma mutação for descoberta em outros tipos de câncer. Resultado da descoberta: no dia de sua divulgação (29 de abril de 2004), a ação da AstraZeneca subiu 67 centavos de dólar, para US\$ 47,39.

\section{Mais um problema ético para a Indústria dos Ensaios Clínicos}

A crescente dificuldade em encontrar pacientes que se adeqüem às exigências de ensaios clínicos e de convencê-los a se engajar neles (como reportado nesta seção, no vol. IV, n. 1, mar.2001) leva a indústria contratada pelo setor farmacêutico a realizá-los no exterior, com frequiência cada vez maior. Por exemplo, uma pequena companhia farmacêutica, a CV Therapeutics, de Palo Alto, Califórnia, espera a aprovação pelo FDA de sua droga contra angina crônica: ensaios clínicos efetuados com 1.014 pacientes - dos quais 600 da Rússia e da Europa do Leste - mostraram bons resultados. Será a primeira droga dita capaz de melhorar a condição de quem tem angina lançada no mercado em 25 anos.

Quem implementou os ensaios na Rússia foi uma companhia baseada em São Petersburgo, formada por seis funcionários e dirigida por um norte-americano, Richard Leach. Ele explicou ao New York Times porque é bom conduzir lá estudos clínicos: há médicos bem formados, ganhando poucas centenas de dólares por 


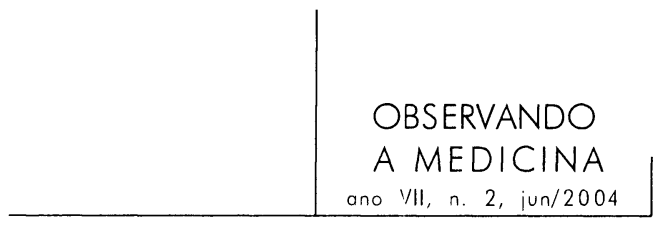

mês - portanto, muito interessados na remuneração oferecida para executar os ensaios; por outro lado, as pessoas se dispõem a participar para ter acesso aos medicamentos, de outra forma completamente fora de seu alcance.

Mas o que acontece com essas pessoas quando o ensaio termina, como ocorrerá em breve com o estudo da CV Therapeutics? Os pacientes que ajudaram a companhia farmacêutica e a implementadora dos ensaios clínicos a obter os dados para a possível aprovação da droga não vão mais ter acesso a ela: como se trata de país pobre (avaliação do jornal), o medicamento provavelmente não será lançado lá; e ambas empresas envolvidas acreditam que não é assunto delas perguntar o que acontece a quem estava tomando os medicamentos quando o estudo acaba.

A situação é pior quando se trata de uma companhia pequena, como a citada - para continuar a fornecer o medicamento em questão, seria necessário montar um esquema de distribuição da droga, que é custoso. Quando, no entanto, o paciente foi engajado num teste clínico nos Estados Unidos, a indústria fornece a droga até que ela seja aprovada. Depois da aprovação, ou o paciente passa a comprá-la (se puder), ou ela lhe será fornecida pelos programas de assistência, mantidos pelo governo ou por empregadores.

\section{Decisão judicial recente sobre administração forçada de antipsicóticos}

Em fevereiro de 2004, a mais alta corte de justiça do Estado de Nova Iorque decidiu que é constitucional a lei que permite aos juízes autorizar a administração forçada de antipsicóticos aos que sofrem de doença mental. A decisão alinha Nova Iorque a outros quarenta Estados. A questão foi levada ao Tribunal pelos advogados de K.L., diagnosticado como portador de transtorno afetivo bipolar, e identificado apenas pelas iniciais. A lei não exige que a pessoa seja declarada mentalmente incapaz por uma corte antes de ser forçada a receber tratamento, o que os advogados consideravam uma violação do direito ao devido processo legal. Eles também se insurgiram contra a permissão dada pela lei de prender por 72 horas, sem direito a audiência, aquela pessoa que se recusar ao tratamento. Mas a corte afirmou que o Estado tem "forte interesse" em "remover imediatamente das ruas" os pacientes sob risco de "causar mal a si próprios ou a outrem' como resultado de sua insurgência contra a medicação. Há três mil pessoas sob medicação forçada no Estado de Nova Iorque. O Judiciário emite a ordem de medicação forçada a pedido da família ou de colegas de trabalho. 


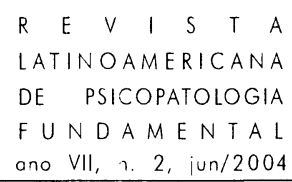

\section{A execução de Charles Laverne Singleton}

No que toca à administração forçada de antipsicóticos a presos para tornálos "elegíveis" para julgamento ou execução (Revista Psicopatologia Fundamental, vol. VI, n. 3, set.2003), a Suprema Corte, em outubro de 2003, manteve o direito do Estado do Arkansas de ministrar antipsicóticos apenas para tornar possível a execução de Charles Laverne Singleton, de outra maneira não "executável" dado o fato de a oitava emenda da Constituição proibir punição cruel, o que ficaria configurado caso Mr. Singleton não estivesse sob efeito de medicamentos, segundo decisões anteriores. O Estado de Arkansas executou-o no dia 6 de janeiro, por injeção letal. Suas últimas palavras foram: "The blind think I'm playing a game. They deny me, refusing me existence. But everybody takes the place of another. As it is written, I will come forth as you go". Estaria ele "mentalmente são"?

\section{Mais uma decisão no cerco à indústria farmacêutica pelas cortes dos EUA}

Como outros 25 Estados norte-americanos interessados em diminuir os gastos com medicamentos que fornece a certos grupos entre seus cidadãos, o Estado de Michigan decidiu estabelecer uma lista de "drogas preferenciais" em quarenta categorias terapêuticas.

Entre as drogas que considera as mais efetivas dentro de cada categoria, o programa Medicaid e os outros dois programas mantidos pelo Estado para favorecer os mais pobres cobrem automaticamente as mais baratas. Outros medicamentos podem ser cobertos pelos programas desde que a indústria ofereça descontos ao Estado, de maneira a baixar os preços ao nível das drogas da lista das preferenciais. Para que as farmácias forneçam essas drogas para beneficiários dos programas, é preciso, então, uma autorização prévia. O sistema fez diminuir o crescimento do gasto anual com prescrições, de $11 \%$ (nos três anos anteriores à entrada em vigor da lista de drogas preferenciais) para 4,2\%.

A ação foi proposta pela associação Pharmaceutical Research and Manufactures of América, a Phrma, definida pelo New York Times como "o lobby dos fabricantes de drogas de marca", contra o Ministro da Saúde, Tommy Thompson, que autorizou o programa de Michigan em 2002. As companhias farmacêuticas contestam a "autorização prévia", pois do ponto de vista deles ela "limita o acesso a certos medicamentos e força pacientes a aceitarem alternativas inferiores de tratamento". A Corte Federal de Apelações do Circuito do Distrito de Columbia sustentou o direito de os Estados exigirem os descontos para 


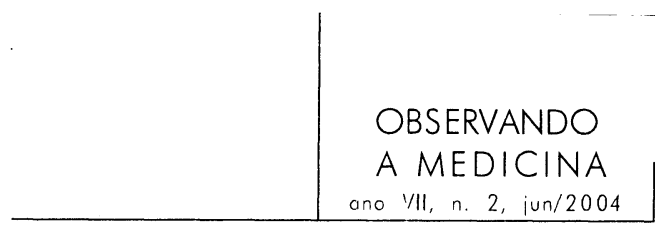

compras dentro dos programas dirigidos aos menos privilegiados. Há mais dez Estados que já aprovaram as leis necessárias para também introduzir as listas de drogas preferenciais. (cf. Revista Latinoamericana de Psicopatologia Fundamental, vol. VI, n. 2, jun.2003)

\section{Efeito placebo}

Há uma empresa baseada em Miami, Flórida, especializada em escolher nomes para produtos farmacêuticos. Entre 1997 e 2003, testou 8.400 denominações para drogas. Foi essa empresa, presidida por James Dettore, que batizou, por exemplo, Lipitor e Allegra - um medicamento para alergia. Segundo ele, as letras X, Z, C e D indicam "subliminarmente" que a droga é poderosa: "Quanto mais forte a tonalidade de um nome, mais eficaz é o produto na mente do médico e o consumidor final", afirmou ele ao New York Times. Ele explicou assim o nome Levitra: vem de "elevar"; quando testado, foi avaliado como "europeu", "elegante", "com conotações de alta classe"; "le" é masculino em francês, e "vitra", continuou, alude a vitalidade.

A indústria farmacêutica pode gastar até meio milhão de dólares na escolha do nome e da embalagem de um medicamento, o que mostra sua crença no poder do nome. E como se calcula que há 12 mil drogas em pesquisa nas fábricas, as marcas são pensadas e reservadas quando o medicamento potencial ainda está na placa de Petri, bem no início do processo de desenvolvimento.

\section{A descrição feita por Hillary Clinton do sistema de cuidados da saúde nos EUA}

A senadora democrata por Nova Iorque faz uma descrição pormenorizada do sistema de saúde norte-americano em artigo publicado em The New York Times Magazine, dia 18 de abril de 2004. Em 1993, a então primeira-dama apresentou e defendeu o projeto do governo Clinton para a reforma do sistema - que propunha uma reviravolta: tornar universal o acesso ao sistema de saúde. Quer dizer, garantir a todo cidadão o direito de receber tratamento - como acontece no Brasil desde a criação do SUS, ou na Grã-Bretanha com o National Health Service, ou no Canadá. O plano elaborado pelo governo Clinton foi derrotado, com grande desgaste para a então primeira-dama e o governo de seu marido. $\mathrm{O}$ 


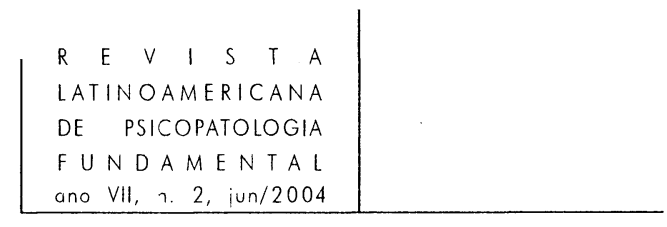

artigo da senadora pretende alertar para o aprofundamento dos problemas antigos que o sistema já vem enfrentando - custos crescentes e crescente número de pessoas sem nenhum tipo de seguro. E chamar a atenção para os problemas novos, que em especial a genética colocará para as seguradoras de saúde e para aqueles que precisam comprar um seguro.

Grosso modo, o acesso ao sistema de saúde norte-americano, que é totalmente privado, permanece organizado até o presente nas bases estabelecidas por Lyndon Johnson: em 1965, o presidente criou os programas Medicare e Medicaid. Pela primeira vez na história do país, o governo se responsabilizou pela cobertura de saúde para certos grupos de necessitados. Através do Medicare, o governo federal compra (recolhe imposto para isso - 1,45\% dos empregados, $1,45 \%$ dos empregadores) assistência à saúde para quem já completou 65 anos ou para quem, embora mais jovem, sofra de certas doenças incapacitantes. Através do Medicaid, co-financiado por fundos federais e estaduais, os Estados se responsabilizam pela assistência básica à saúde a determinados grupos mais vulneráveis entre os norte-americanos mais pobres.

Fora disso, na maior economia do mundo, acesso a tratamento de saúde é exclusividade de quem dispõe de um seguro de saúde privado, comprado em geral pelo empregador do beneficiário (o governo dos Estados Unidos é um dos empregadores que contratam o seguro-saúde de seus funcionários), ou pelo próprio interessado. Nas palavras de Hillary, a diferença entre o sistema norteamericano e o praticados pelos "rivais econômicos mais próximos dos Estados Unidos" é que eles "têm sistemas nacionais obrigatórios de assistência à saúde, ao invés do modelo voluntário baseado no empregador que temos aqui". Ela explica a diferença, em termos "econômicos": empresas canadenses e norteamericanas pagam impostos para financiar a saúde; mas as empresas norte americanas pagam também pelo seguro-saúde de seus empregados. Segundo Clinton, sobre cada carro médio produzido pela indústria automobilística, o fabricante paga cerca de US\$1.300 para o seguro-saúde de seus empregados.

É o que se diz: os custos da saúde são crescentes. O gasto já representa $15 \%$ do Produto Nacional Bruto - US\$1,6 trilhões; em 2013, estimativas indicam que chegará a 18,4\% do PNB. Entre os problemas menos conhecidos do sistema americano, Hillary aponta a ineficiência: um em cada quatro dólares gastos vai para a administração da indústria da saúde. Um em cada cinco exames de raio X ou de laboratório são realizados apenas porque o resultado do mesmo exame feito anteriormente não foi encontrado. Um terço de todo o dispêndio ou é duplicação, ou não melhora, ou faz mais mal à saúde do paciente.

O gasto cresce, e a assistência piora - eis o problema dos americanos. Em 1993, diz Hillary, havia 37 milhões de pessoas sem seguro-saúde. Em 2004, são quase 44 milhões. Uma pequena parte dessas pessoas poderia pagar por seu 


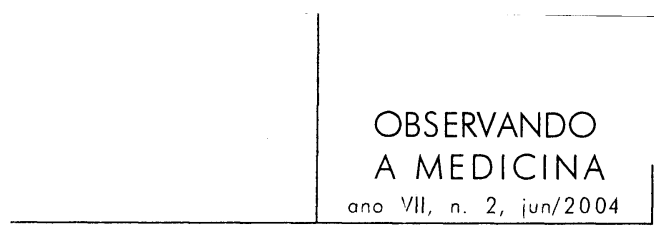

seguro. Mas, para elas, a questão é ser aceita pelas seguradoras. Por exemplo, uma prática do mercado é aceitar cobrir a assistência à saúde de alguém com asma, desde que o asmático aceite que todo o seu sistema respiratório seja excluído da cobertura. Aqui, a genética mostra face perversa: segundo estudos publicados em The Journal of American Medical Association, seis em cada dez mulheres sob risco de ter uma predisposição ao câncer de mama ou de ovário recusam-se a fazer o teste porque isso tornaria o preço de seu seguro-saúde muito mais alto. Pessoas com perfil genético que torne o desenvolvimento de uma doença altamente provável não são aceitas de maneira nenhuma pelas companhias de seguro. Para elas, um seguro-saúde torna-se impossível de ser obtido. A senadora Clinton apresenta ainda outros dados e argumentos. A última frase de seu artigo: "O sistema presente é insustentável. A única questão é se vamos dominar a mudança, ou sermos dominados por ela".

\section{Possível deficiência imunológica psíquica}

Muitos de nós temos pequenos tumores sem saber disso. De fato, autópsias em pessoas que morreram em razão de trauma, freqüentemente revelam colônias microscópicas de células cancerosas, também conhecidas como tumores in situ. Em mais de um terço das autópsias de mulheres entre quarenta e cinqüenta anos, que não tiveram câncer durante a vida, tumores in situ são encontrados em seus seios. Mas só $1 \%$ das mulheres dessa faixa etária apresentam diagnóstico de câncer no seio. Observações similares também são relatadas para câncer de próstata em homens. Virtualmente todas as pessoas entre cinquienta e setenta anos autopsiadas têm carcinomas in situ na tireóide. Por isso, há muito intriga médicos e cientistas por que o câncer se desenvolve e se torna letal em apenas uma pequena percentagem das pessoas.

Essas são as primeiras linhas do ensaio "Câncer sem doença", de Judah Folkman e Raghu Kalluri, da Escola de Medicina de Harvard, publicado na revista Nature, v. 427, 26 de fevereiro de 2004. O pesquisador Judah Folkman observou, há trinta anos, que o crescimento de tumores implica a multiplicação da formação de vasos sanguíneos ("angiogênese") e propôs que inibir essa multiplicação pode impedir o desenvolvimento dos tumores. Mas por que será, afinal, que certos humanos se defendem dos tumores, e outros não? 